\title{
Study of Risk Factors for Foot Ulceration in Type 2 Diabetes Mellitus Patients with Special Reference to HBA1C
}

\author{
DrGajendra $\mathrm{R}^{1}$, Dr Suresh Harsoor ${ }^{2}$, Dr Suresh Chincholi ${ }^{3}$ \\ 1.Post Graduate, Dept of General of medicine, MahadevappaRampure Medical College , \\ Kalaburgi , Karnataka. \\ 2.Professor,Dept of General of medicine, MahadevappaRampure Medical College , \\ Kalaburgi , Karnataka. \\ 3.Professor and HOD, Dept of General of medicine, MahadevappaRampure Medical College , \\ Kalaburgi , Karnataka.
}

\begin{abstract}
Background And Objectives:India, one of the largest countries in the Southeast Asian region, has more than 67 million people with diabetes. With an aging population and the increase in prevalence of DM in the younger age group, the secondary complications are common. Foot problems in diabetes needs increasing attention in view of the fact that they account for $85 \%$ of the non- traumatic lower extremity amputations and cause significant morbidity and mortality. The aim is to study the risk factors for foot ulceration in type 2 DM patients in Basaveshwara Teaching \& General Hospital (BTGH), Gulbarga. and to educate patients with risk factors regarding foot care.

Methods:A total of 50 type 2 DM patients from Basaveshwara Teaching \& General Hospital (BTGH), Gulbarga over a period of 1 year formed the study population. Detailed clinical examination including of the feet was done. Risk factors were assessed by $10 \mathrm{~g} / 5.07$ monofilament and ABI (ankle brachial index) for peripheral sensory neuropathy and peripheral vascular disease respectively. Glycemic control was assessed by HBAlc.

Results:The prevalence of neuropathy, PVD, foot deformities are $48.0 \%, 16.0 \%, 18.0 \%$ respectively. $6.0 \%$ had a history of previous ulcer or amputation. $64.0 \%$ are unaware that diabetes can cause foot problems and $56.0 \%$ of the study population walk bare foot. Statistically significant association $(P<0.05)$ was found between increasing duration of diabetes, worsening glycemic control, increasing age and the prevalence of neuropathy, $P V D$ and foot deformities.

Interpretation And Conclusion :Use of simple screening techniques such as monofilament testing and ABI can help in identifying the foot at risk. Patient education, glycemic control, and regular foot examination by a trained health professional can prevent the occurrence of foot ulcers and amputations.
\end{abstract}

Keywords:Type 2 Diabetes Mellitus ; foot ulcers; Risk factors; Screening; Peripheral neuropathy; Peripheral vascular disease; Monofilament test; Ankle brachial index.

\section{Introduction}

Diabetes Mellitus is the commonest endocrine disorder in the population. Theclinical syndrome is due to either absolute or relative deficiency of insulin .Thenumber of people with type 2 diabetes mellitus (T2DM) is increasing rapidly and the latest figures are 387 million people with diabetes globally which is projected to rise to 592 million people in $2035{ }^{1}$ The diabetes related foot complications are the leading cause of non-traumatic lower extremity amputation and the commonest reason for individuals with diabetes mellitus to be admitted to hospital. Every year $5 \%$ of diabetic patients will develop a foot ulcer. ${ }^{2}$ The foot ulcer incidence rates range between $2 \%$ and $10 \%$ among patients with diabetes mellitus ${ }^{3}$. The age adjusted annual incidence for nontraumatic lower limb amputations in diabetic persons ranges form 2.1 to 13.7 per 1000 persons. $^{4}$

The direct and indirect costs in the treatment of diabetes related foot complications are enormous and impose a huge economic burden on the individual and the health care system. ${ }^{5}$ Various risk factors like peripheral neuropathy, peripheral vascular disease, foot deformities etc., lead to the development of foot ulcers and subsequent infection and amputation. This study is hence conducted to identify the various known risk factors for foot ulcerations in type 2 diabetics. Early recognition of diabetic patients with at-risk feet will help in initiating preventive measures including patient education regarding foot care and thereby decrease the morbidity and mortality as well as the emotional and economic consequences associated with diabetic foot ulcers.

\section{Materials And Methods}

This is a cross-sectional observational study on type 2 diabetic patients in Basaveshwara Teaching \& General Hospital (BTGH), Gulbarga , during a period of 1 year from June 2015 to May 2016. Patients attending 
the opd as well as those admitted in the wards were included in the study.Atotal of 50 patients were enrolled in the study after fulfilling inclusion and exclusion criteria. Informed consent was obtained from all subjects after the procedures involved were fully explained.

\section{Inclusion criteria}

- History of type 2 diabetes mellitus, on insulin or oral hypoglycemic agents or both.

Exclusion criteria :

- Patients with newly diagnosed diabetes mellitus on admission.

- Type 2 diabetics with overt foot ulceration / gangrene.

- Type 2 diabetic patients with foot lesions secondary to recent trauma (eg: burns, road traffic accidents etc.)

- Type 2 diabetics with spinal cord injuries.

- Diabetic patients with infectious diseases that can involve peripheral nerves (eg: Leprosy).

- Type 2 diabetic patients who are alcohol abusers (as identified by a score of $\geq 3$ on CAGE questionnaire).

- $\quad$ Type 2 diabetics with TAO (Thromboangiitis obliterans).

- Type 2 diabetics with acute illnesses like myocardial infarction, cerebro vascular accidents, diabetic ketoacidosis, hypoglycemia etc.

A pre-tested pre-structured proforma was used to record history details,including duration of diabetes, smoking history, bare foot walking, previous foot ulceration or amputation, awareness about foot complications in diabetes,mode of treatment and symptoms of neuropathy and vasculopathy. A thorough physical examination including the examination of the feet was done.Evidence of peripheral sensory neuropathy in the feet was established using a $10 \mathrm{gm} / 5.07$ semmes-Weinstein monofilament at four plantar sites(great toe and base of $1 \mathrm{st}$, 3rd and 5th metatarsal heads). Each filament was placed against the plantar surface of the foot in a perpendicular fashion so that it bent with a constant force, with the $10 \mathrm{gm}$ filament. With eyes closed,the patients were required to elicit a yes/no response to monofilament pressure and correctly identify the site of contact. Insensitivity to $10 \mathrm{~g}$ monofilament at any one site on either foot indicated loss of protective sensation.Evidence of peripheral vascular disease was assessed using anklebrachial index (ABI) and palpation of pedal pulses (dorsalis pedis and posterior tibial arteries).ABI $=$ Systolic BP at ankle $/$ Systolic BP at elbow

The patient was placed in recumbent position for 5 minutes. Then the systolic blood pressure in both arms is measured using a sphygmomanometer and inflatable cuff tied above the elbow. The higher of the two values is used for the brachial portion of the index. The systolic blood pressure in the ankles is then measured using the dorsalis pedis and posterior tibial arteries with the inflatable cuff placed just above the ankle. A Doppler probe is used and the pressure at which the acoustic pulse signal returns after deflating the cuff is noted. The higher of the ankle systolic pressure value is used for calculating the ankle portion of the index. An ABI of 0.9 or less is taken as evidence of PVD.Examination of the feet was done and the presence of any foot deformities (Hallux valgus, claw toes, prominent metatarsal heads, pescavus) was noted.Blood samples were taken for estimation of glycosylated hemoglobin (HBA1c) and glycemic control was evaluated as good control (HBA1c < 7.5\%), fair control (HBA1c between 7.6\% - 9.0\%) and poor control (HBA1c > 9.1\%).

\section{Results}

In the study out of 50 patients with type 2 diabetes mellitus ranging the age from 32 years to 84 years (31 men, 19 women), mean age and standard deviation of men is $60.29 \pm 11.96$ and women is $57.57 \pm 13.73$, overall is $59.26 \pm 12.59$ comprised the study group. Most patients were in the age spectrum of 51-70 years. Male: Female ratio is 1.6:1. There is no statistical significant difference of age among males and females $(\mathrm{p}>0.05)$. The duration of diabetes in the study population ranged from 1 year to 18 years. Mean duration is $\mathbf{6 . 4 8}$ years \pm SD 3.79. Most patients were in the duration spectrum of 6-10 years i-e $25(50.0 \%)$, followed by the duration spectrum of 1-5 years $19(38.0 \%)$ cases. The $\mathbf{H B} \mathbf{A}_{1 \mathbf{C}}$ values in the study population ranged from $\mathbf{7 . 1 \%}$ to $11.5 \%$. The mean $\mathbf{H B A}_{1 \mathrm{C}}$ is $\mathbf{9 . 2 0 \%} \pm \mathbf{S D} \mathbf{0 . 9 2}$. Majority of the patients in the study population were having poor glycemic control as evidenced by $\mathbf{H B A}_{1 \mathrm{C}} \square \mathbf{9 . 1 \%}$ i-e 27 ( $54.0 \%$ ) cases. Fair glycemic control as evidenced by $\mathrm{HBA}_{1 \mathrm{C}}$ between $\mathbf{7 . 6}$ - 9.0\% was seen in $20 \mathbf{( 4 0 . 0 \% )}$ ) cases.In the study subjects.Good glycemic control (HBA $\left.\mathbf{A C}_{1 \mathrm{C}} \square \mathbf{7 . 5 \%}\right)$ was observed only in $\mathbf{3}(\mathbf{6 . 0 \%})$ cases In the study.

\section{Pie Diagram Represents Degree Of Glycemic Control In The Study Population}

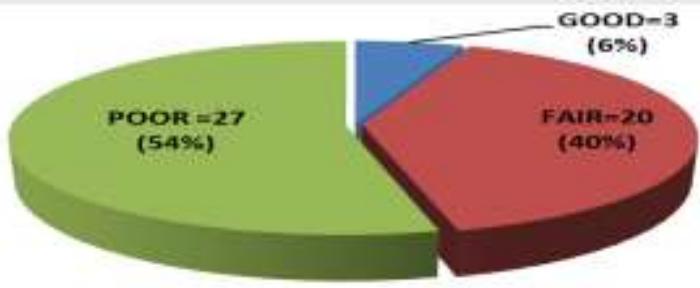

$=$ GOOD $(\leq 7.5)=\operatorname{FAIR}(7.6-9.0)=\operatorname{POOR}(29.1)$ 
Prevalence of neuropathy (as evidenced by foot insensitivity to monofilament testing) was 24 (48.0\%) among 50 patients. Prevalence of peripheral vascular disease (as evidenced by $\mathrm{ABI} \leq 0.9)$ was $8(16.0 \%)$ among 50 patients. 7 (14.0\%) patients had evidence of both neuropathy and PVD. $3(6.0 \%)$ patients had a previous ulcer or amputation among 50. Prevalence of foot deformities is 9 (18.0\%) among 50 patients. Among the foot deformities, Hallux valgus was the most common $(n=3)$, followed by prominent metatarsal heads $(n=2)$, claw toes $(\mathrm{n}=2)$ and pes cavus $(\mathrm{n}=2) .18(36.0 \%)$ patients among the 50 study group are aware that diabetes can lead to loss of sensation in the feet with risk of ulceration and amputation. 32 patients $(64.0 \%)$ are unaware that diabetes can lead to Foot problems.Among 50 study subjects 28 (56.0\%) of the study population practice bare foot walking while $22(44.0 \%)$ patients wear footwear.

Study revealed that, with worsening glycemic control, the prevalence of neuropathy (as evidenced by monofilament test $)$ increased in the study group $\left(X^{2}=18.76, P<0.001\right.$ which is statistically veryhighly significant). Similarly the prevalence of PVD (as evidenced by ABI $\leq 0.9$ ) and foot deformities in the study group increased with poor glycemic control $\left(X^{2}=8.76, P<0.01 ; X^{2}=9.4, P<0.01\right.$ respectively which are statistically significant).

Table 1: Comparison Between Glycemic Control and Risk Factors For Foot Ulceration

\begin{tabular}{|c|c|c|c|c|c|c|c|c|c|}
\hline \multicolumn{2}{|l|}{ Risk Factors } & \multirow{3}{*}{\begin{tabular}{|l|}
$\begin{array}{l}\text { No. Of } \\
\text { cases }\end{array}$ \\
24
\end{tabular}} & \multicolumn{2}{|c|}{$\begin{array}{l}\text { Good Control } \\
(\square 7.5 \%)\end{array}$} & \multicolumn{2}{|c|}{$\begin{array}{l}\text { Fair Control } \\
(7.6 \%-9 \%)\end{array}$} & \multicolumn{2}{|c|}{$\begin{array}{l}\text { Poor Control } \\
(>9 \%)\end{array}$} & \multirow[t]{2}{*}{$\begin{array}{l}\square^{2} \text { test value, } \\
\text { P-value \& significance }\end{array}$} \\
\hline & & & No. & $\%$ & No. & No. & $\%$ & $\%$ & \\
\hline \multirow[t]{2}{*}{ Neuropathy } & $+\mathrm{VE}$ & & 0 & 0.0 & 7 & 29.2 & 17 & 70.8 & \multirow{2}{*}{$\begin{array}{l}\square^{2}=18.76 \\
P<0.001, \text { VHS }\end{array}$} \\
\hline & $-\mathrm{VE}$ & 26 & 3 & 11.5 & 13 & 50.0 & 10 & 38.5 & \\
\hline \multirow[t]{2}{*}{ PVD } & $+\mathrm{VE}$ & 8 & 0 & 0.0 & 2 & 25.0 & 6 & 75.0 & \multirow{2}{*}{$\begin{array}{l}\square^{2}=8.76 \\
\text { P<0.01, HS }\end{array}$} \\
\hline & $-\mathrm{VE}$ & 42 & 3 & 7.2 & 18 & 42.8 & 21 & 50.0 & \\
\hline \multirow{2}{*}{$\begin{array}{l}\text { Foot } \\
\text { deformities }\end{array}$} & $+\mathrm{VE}$ & 9 & 0 & 0.0 & 1 & 11.1 & 8 & 88.9 & \multirow{2}{*}{$\begin{array}{l}\square^{2}=10.52 \\
P<0.01, \text { HS }\end{array}$} \\
\hline & $-\mathrm{VE}$ & 41 & 3 & 7.3 & 19 & 46.3 & 19 & 46.4 & \\
\hline
\end{tabular}

With increasing duration of diabetes, the prevalence of neuropathy, peripheral vascular disease and foot deformities in the study population also increased. $\left(X^{2}=36.4, P<0.001 ; X^{2}=17.9, P<0.001 ; \quad X^{2}=41.8, P<0.001\right.$ respectively which are statistically very highly significant).

Table 2: Comparison between duration of diabetes and risk factors for foot ulceration

\begin{tabular}{|c|c|c|c|c|c|c|c|}
\hline \multirow{2}{*}{$\begin{array}{l}\text { Duration of diabetes } \\
\text { ( in years) }\end{array}$} & \multirow{2}{*}{$\begin{array}{l}\text { No.Of } \\
\text { Cases }\end{array}$} & \multicolumn{2}{|c|}{ Neuropathy } & \multicolumn{2}{|c|}{ PVD } & \multicolumn{2}{|c|}{ Foot Deformities } \\
\hline & & No. & $\%$ & No & $\%$ & No & $\%$ \\
\hline $1-5$ & 19 & 3 & 15.7 & 1 & 5.2 & 0 & 0.0 \\
\hline 6-10 & 25 & 16 & 64.0 & 4 & 16.0 & 4 & 16.0 \\
\hline 11-15 & 4 & 3 & 75.0 & 2 & 50.0 & 3 & 75.0 \\
\hline$\square 16$ & 2 & 2 & 100.0 & 1 & 50.0 & 2 & 100.0 \\
\hline $\mathbf{X}^{2}$ & $\mathrm{~N}=50$ & \multicolumn{2}{|c|}{36.4} & \multicolumn{2}{|c|}{17.9} & \multicolumn{2}{|c|}{41.8} \\
\hline P-value\& sig. & -- & \multicolumn{2}{|c|}{$P<0.001$, VHS } & \multicolumn{2}{|c|}{$P<0.001$, VHS } & \multicolumn{2}{|c|}{$P<0.001$, VHS } \\
\hline
\end{tabular}

With increasing age in the study population, the prevalence of neuropathy, PVD and foot deformities increased $\left(X^{2}=47.9, P<0.001 ; \quad X^{2}=38.8, P<0.001 ; \quad X^{2}=42.5, P<0.001\right.$ respectively which are statistically very highly significant). 13 men and 11 women in the study population had evidence of neuropathy $\left(\mathbf{X}^{2}=\mathbf{0 . 5 2}\right.$, $\mathbf{P}=\mathbf{0 . 4 5 3}$ which is statistically not significant $) .4$ men and 4 women had evidence of $\operatorname{PVD}\left(X^{2}=\mathbf{0 . 0 1}, \mathbf{P}=\mathbf{0 . 7 4 2}\right.$ which is statistically not significant $) .5$ men and 4 women had foot deformities $\left(X^{2}=\mathbf{0 . 6 7}, P=\mathbf{0 . 4 8 2}\right.$ which is statistically not significant).

\section{Discussion}

This study correlates with another study done in South India by chanda et al. where the prevalence of neuropathy was found to be $64.1 \% .{ }^{6} \mathrm{~A}$ study done by Chaturvedi et al, has shown the prevalence of neuropathy as $30 \%$ and that most of foot problems associated with diabetes in India are neuropathic and infective in origin. ${ }^{7}$ A multicentric study from India has shown the prevalence of neuropathy in subjects with age $>50$ years as $72 \%{ }^{8}$ This is comparable with the present study where prevalence of neuropathy increased with increasing age of the study subjects. These findings correlate with a population based study by Manes et al where age, diabetes duration and glycemic control but not gender were found to be significant risk factors for diabetic neuropathy. ${ }^{9}$

A study by Malgrange et al has found the prevalence of PVD to be $17 \%$ which is comparable with our study. ${ }^{10} \mathrm{~A}$ study by Wilkblad et al has determined the prevalence of PVD in $12.5 \%$ of patients. ${ }^{11}$

The present study has also demonstrated that prevalence of PVD increases as the age of the study subjects increase. This is comparable with a study by Premalatha et al which has shown that prevalence of PVD increased with age. ${ }^{12}$ The prevalence of structural foot deformities in the present study was $18.0 \%$. This is comparable with another hospital based study that has found the prevalence of foot deformities to be $21.1 \%{ }^{10}$ 
The present study found that $6.0 \%$ patients had a previous foot ulcer or amputation. This study is comparable to a study by Maigrange et al, which documented that $7.2 \%$ of the study population had a previous ulcer or amputation. ${ }^{10}$ The prevalence of bare foot walkers in the present study was $56.0 \%$. This was comparable with another study done in South India where the prevalence of bare foot walking among the study population was around $60 \% .{ }^{13}$ In a similar study from India by Chanda et al, $35.8 \%$ are aware about the complications of peripheral neuropathy caused by diabetes. ${ }^{6}$

\section{Conclusion}

In the present study population of 50 type 2 diabetic subjects Prevalence of neuropathy in the feet is $48.0 \%$. Prevalence of peripheral vascular disease is $16.0 \%$, Prevalence of foot deformities is $18.0 \%$, Prevalence of patients with previous ulcer or amputation is $6.0 \%, 36 \%$ are aware that diabetes can lead to loss of sensation in the feet with risk of ulceration and amputation, $56 \%$ practice bare foot walking. Worsening glycemic control is significantly associated with increase in prevalence of neuropathy, PVD and foot deformities, which in turn increase the risk of foot ulceration. Increasing duration of diabetes is also significantly associated with increase in neuropathy, PVD and foot deformities. Age is an independent risk factor. With advancing age, neuropathy, PVD and foot deformities have significantly increased. Gender is not significantly associated with neuropathy, PVD and foot deformities. To conclude, management of diabetic foot problems requires multidisciplinary approach and should include the services of a physician, podiatrist, surgeons, orthopaedist, physical and occupational therapist, orthotist and a social worker. Apart from them, the family members of the patient and the patient themselves should be actively involved in the care.

\section{Bibliography}

[1]. International Diabetes Federation. IDF Diabetes Atlas update poster, $6^{\text {th }}$ edition. Brussels, Belgium: International Diabetes Federation, 2014. [online] Available from http:// www.idf.org/diabetesatlas/update-2014 [Accessed December, 2014].

[2]. Shah SF, Hameed S, Khawaja Z, Abdullah T, Waqar SH, Zahid MA. Evaluation and management of diabetic foot: A multicentre study conducted at Rawalpindi, Islamabad. Ann Pak inst Med Sci. 2011;7(4):233-237.

[3]. Hunt D. Using evidence in practice : Foot care in diabetics. EndocrinolMetabClin N Am 2002; 31(3): 603-11.

[4]. Reiber GE. Epidemiology of foot ulcers and amputations in the diabetic foot. In: Bowker JH, Pfeifer MA, eds. The diabetic foot. St.Louis, MO: Mosby, 2001 .p.13-32.

[5]. Ramachandran A, Snehalatha C, Viswanathan V. Burden of type 2 diabetes and its complications - the Indian Scenario. CurrSci 2002; 83(12): 1471-76.

[6]. Chanda A, Ayyar V, Idiculla JM, Bantwal 6. Perception of foot problems among diabetic patients : A cross sectional study. Tnt 3 Diab Dev Ctries 2006; 26: 77-80

[7]. Chaturvedi N, Abbot CA, Whalley A, Widdows P, Leggetter SY, Boulton AJM. Risk of diabetes related amputation in south Asian Vs Europeans in the UK. Diabet Med 2002; 19: 99-104.

[8]. Viswanathan V, Thomas N, Tandon N, Asirvtham A, Rajasekhar S, Ramachandran A, et a!. Profile of diabetic foot complications and it's associated complications - A multicentric study from India. J Assoc Physicians India 2005; 53: 933-36.

[9]. Manes CH, Papazoglou N, Sossidou E, Soulis K, Milarakis D, Satsoglov A, et al. Prevalence of diabetic neuropathy and foot ulceration : identification of potential risk factors - A population based study. Wounds 2002; 14(1): 11-15.

[10]. Malgrange D, Richard JL, Leymarie F. Screening diabetic patients at risk for foot ulceration. A multicentre hospital based study in France. Diabetes Metab 2003; 29: 261-8.

[11]. Wilkblad K, Smide B, Bergstrom A, Keni J, Mugusi F. Outcome of clinical foot examination in relation to glycemic control. Diab Res ClinPract 1997; 37(3): 185-92.

[12]. Premalatha G, Shanthirani CS, Deepa R, Markovitz J, Mohan V. Prevalence and risk factors of peripheral vascular disease in selected south Indian population. The Chennai urban population study. Diabetes Care 2000; 23: 1295-1300.

[13]. Elango G, Venugopal V. Profile of diabetic foot-our experience at Perundurai Medical College Hospital. J Assoc Physicians India 2003;57: 1225 . 